\title{
LA ASOCIACIÓN DE PRODUCTORES DE SALITRE Y EL FUNCIONAMIENTO DE SU DEPARTAMENTO DE BIENESTAR SOCIAL. TARAPACÁ Y ANTOFAGASTA, 1921-1930
}

\author{
THE NITRATE PRODUCERS ASSOCIATION AND THE OPERATION OF ITS \\ DEPARTMENT OF SOCIAL WELFARE. TARAPACÁ AND ANTOFAGASTA, \\ 1921-1930
}

Julio Aguilera Ferreira*

\begin{abstract}
Se estudia el funcionamiento del Departamento de Bienestar de la Asociación de Productores de Salitre durante la década de 1920, organismo destinado a mejorar las condiciones de vida de los obreros y de sus familias en las provincias de Tarapacá y Antofagasta. Las actividades de esta entidad no solo incluyeron aspectos propios del bienestar, sino también constituyó un sistema de provisión de mano de obra en un contexto de crisis de la industria salitrera. Estas iniciativas buscaron disminuir el radicalismo obrero, aumentar la productividad, mejorar su salud y disminuir el costo de vida en los campamentos. No obstante, la aplicación de este programa de bienestar experimentó primero dificultades con las propias compañías que integraban la Asociación y posteriormente por la creciente intervención estatal en materias sociales.

Palabras claves: Minería, organizaciones patronales, relaciones laborales, bienestar social.
\end{abstract}

The development of the Welfare Department of the Nitrate Producers Association were studied during the 1920s, the organization aimed at improving the living conditions of workers and their families in the provinces of Tarapacá and Antofagasta. The activities of this entity not only included aspects of welfare, but also constituted a system of labor supply in a context of crisis of the nitrate industry. These initiatives sought to reduce workers' radicalism, increase productivity, improve health and reduce the cost of living in the camps. However, the implementation of this welfare program first experienced difficulties with the companies that were part of the Asociación and later on by the increasing state intervention in social matters.

Key words: Mining, employers' organizations, labor relations, social welfare.

\section{Introducción}

En enero de 1921 la oficina San Gregorio, que estaba ubicada en la provincia de Antofagasta, debió suspender sus actividades debido a la crisis por la que atravesaba la actividad tras la Primera Guerra Mundial. La paralización generó una amplia movilización obrera en la región, la que concluyó violentamente el 3 de febrero con la muerte de varios policías, del administrador de la oficina y de por lo menos de unos 40 obreros, aunque la cifra nunca ha estado del todo clara (Recabarren, 2010). Los eventos de San Gregorio motivaron al gobierno a buscar alternativas de mejoramiento de las condiciones de vida de los trabajadores, para ello el ministro del interior Pedro Aguirre Cerda "recomendó" a la Asociación de Productores de Salitre (en adelante APS o Asociación) ${ }^{1}$ que mejorara las condiciones de vida de los obreros, amenazando que de lo contrario se vería obligado a denunciar que los trabajadores "vivían en forma inhumana" si no se concretaba esta propuesta $^{2}$, la que fue acogida por la APS al crear su Departamento de Bienestar. Esta respuesta del Estado y de los patrones a las demandas obreras contrasta con la habitual indiferencia que estas entidades habían mostrado ante las miserables condiciones de vida de los obreros del salitre y de sus familias, y a la falta de efectividad de las pocas medidas adoptadas con el fin de revertirlas, lo que constituyó una novedad en la década de 1920.

Salvo por algunas páginas que Floreal Recabarren destinó acerca de la creación del Departamento de Bienestar de la APS (2010: 36-37), las iniciativas de bienestar social de la minería del salitre no habían sido estudiadas. La historiografía social respecto del ciclo salitrero es extensa y ha estado focalizada en el análisis de la política y movilización obrera, en las condiciones de la vida cotidiana en la pampa o en una combinación de ellas (Bravo Elizondo y Berryy-Bravo 2012; Devés 1997; González Miranda

* Investigador independiente. Correo electrónico: julioaguileraf@ gmail.com 
2002; González Miranda 2013; Pinto y Valdivia 2001; Pinto 1998, entre otros). Solo recientemente Pablo Artaza (2016) dedicó un artículo a las causas que dieron origen a esta entidad, con énfasis en el estudio de las relaciones entre la patronal y el Estado entre 1921 y 1924, periodo en el que la presión gubernamental de Alessandri empujó a la APS a crear el Departamento de Bienestar. Artaza describe con detalle la estructura del Departamento de Bienestar y las discusiones que se originaron en el seno del directorio de la Asociación durante dicho periodo e identifica que el principal campo de acción del Departamento estuvo "mucho más directamente hacia el control y la adecuada selección de la mano de obra", más que a la misión de lograr el bienestar obrero (Artaza 2016: 63). El presente artículo asume la investigación de Artaza como una base, profundizando en aquellas actividades desarrolladas por el Departamento de Bienestar durante toda la década de 1920 , con foco tanto en las iniciativas propiamente de bienestar obrero como en los elementos de control social, así como la posición que adoptaron las compañías y otros actores relevantes en relación con las propuestas de la Asociación. Otras iniciativas de bienestar en la minería chilena han sido abordadas en el marco de investigaciones concernientes a los trabajadores y la industria cuprífera, actividad que inauguró la presencia de departamentos de bienestar en Chile en la segunda mitad de la década de 1910 (Klubock 1998; Vergara 2008) y del carbón (Pavilack 2011), pero solo en el último tiempo las políticas empresariales de bienestar industrial han comenzado a ser revisadas de forma más sistemática, principalmente en atención con las estrategias de control social propias del paternalismo industrial, aunque enfocadas en experiencias distintas a las del salitre (Brito y Ganter 2014; Godoy 2015; Venegas 2014; Venegas y Morales 2014; Venegas, Videla y Godoy 2016).

La década de 1920 inauguró un nuevo periodo en las relaciones laborales entre las empresas y los trabajadores en Chile, especialmente en aquellas que tenían campamentos para sus trabajadores. Este periodo estuvo marcado por la irrupción de políticas empresariales destinadas a mejorar las condiciones de vida de la clase obrera, las que pueden ser entendidas bajo el rótulo de paternalismo industrial o paternalismo de bienestar (Wray, 1996). Pero a diferencia del paternalismo más clásico en el que el patrón establecía relaciones protectoras directas con los trabajadores (Venegas 2014:5), los departamentos de bienestar actuaron institucionalizando dichas relaciones, las que se cruzaron con elementos de gestión racional del trabajo como el fordismo y el taylorismo, fenómeno que también ocurrió en otras industrias latinoamericanas entre las décadas de 1920 a 1950 (Farnsworth-Alvear 200:153-154; Martínez Varas 2006; Weinstein 1996:32).

Este artículo tiene por objetivo identificar las maneras en que las iniciativas de bienestar social se expresaron en la década de 1920 en la industria salitrera. Para esto se recurrió a fuentes de la propia APS, especialmente las actas del directorio y el boletín que la misma Asociación publicó, así como a otras fuentes periódicas y estatales. El foco en las acciones de bienestar social es crucial para la comprensión de la historia de las relaciones laborales de mediados del siglo XX, ya que los sistemas de bienestar social y las relaciones industriales que se crearon en la década de 1920 fueron la principal arena de lucha de la clase obrera en las dos décadas siguientes (Pavilack 2011:35). De ahí la importancia de análisis que permitan aproximaciones diversas a su estudio.

\section{Los primeros años del Departamento de Bienestar de la Asociación de Productores de Salitre}

En 1919 la comisión parlamentaria que recorrió las provincias de Tarapacá y Antofagasta constató las miserables condiciones laborales y de vida de los trabajadores salitreros, que estaban caracterizadas por largas jornadas de trabajo, viviendas insanas, precios elevados de los artículos de primera necesidad y falta de servicios sanitarios y médicos ${ }^{3}$. Estas condiciones de vida fueron reconocidas por la APS y se establecieron en la base del programa de bienestar que organizó. Tal como constató Pablo Artaza (2016), el surgimiento del Departamento de Bienestar de la Asociación fue el resultado de la conjugación de intereses estatales y patronales para mejorar las condiciones de vida de los trabajadores salitreros y modernizar sus relaciones industriales.

El Departamento comenzó sus funciones a mediados de 1921 con dos actividades: visitas a las oficinas salitreras por parte de empleados del Departamento para difundir sus principios ${ }^{4}$ y el establecimiento de un sistema de contratación de obreros destinado a reemplazar las prácticas abusivas del enganche. Durante décadas el enganche fue el principal sistema de provisión de mano de 
obra en las salitreras, pero no incluía ningún tipo de seguridad para los trabajadores en caso de despido o que las condiciones pactadas inicialmente entre el trabajador y el enganchador fueran cambiadas en las oficinas (González Miranda 2002:141-151; Monteón 1979). La APS organizó la contratación de trabajadores y elaboró un reglamento de enganche, creó un sistema de identificación de los obreros y abogó por mejoras en los medios de transporte utilizados para este fin ${ }^{5}$. Dicho sistema aseguraba a los trabajadores su traslado, colocación en una oficina, un desahucio en caso de despido y un pasaje de regreso al centro del país, lo que en la práctica operó como un verdadero contrato escrito antes de que esta figura existiera legalmente. El primer contingente de trabajadores contratados con las nuevas disposiciones se embarcó desde Valparaíso con destino a Taltal a fines de 1922: 60 hombres, 26 mujeres y 35 niños ${ }^{6}$. La labor de los inspectores regionales de la asociación fue fundamental para difundir estas medidas entre las compañías ${ }^{7}$, pero su recepción de estas no siempre fue positiva, especialmente en la aplicación de la reglamentación. Con el fin de presionar por su cumplimiento, el directorio de la APS estableció multas en torno a las $£ 100$ a los asociados que lo contravinieran ${ }^{8}$.

El Departamento creó una oficina permanente de contratación en Valparaíso, en la que se realizaban exámenes médicos a los obreros y se los subsidiaba en la obtención de sus documentos de identificación ${ }^{9}$. Hacia noviembre de 1923, el Departamento había trasladado a 13 mil obreros, sin considerar mujeres y niños ${ }^{10}$. Sin embargo, hubo problemas recurrentes en la contratación de trabajadores en el centro y el sur del país, pues agricultores, industriales y autoridades ponían trabas a la Asociación, principalmente en los meses de verano que coincidían con las cosechas ${ }^{11}$. La Asociación intentó contratar obreros extranjeros, pero resultó dificultoso, especialmente si se trataba de obreros bolivianos o peruanos ${ }^{12}$. Paralelamente, la APS recomendó a sus asociados mejorar la construcción de las viviendas, dar a conocer medidas de higiene, vender al costo los artículos de primera necesidad, permitir el ingreso de vendedores ambulantes, prohibir la venta de bebidas alcohólicas, instalar pequeños hospitales, establecer entretenimientos que evitaran que el obrero saliera de los campamentos en sus horas libres y nombrar a un encargado de bienestar que auxiliara a los administradores de cada oficina $^{13}$.
En suma, la labor más importante del Departamento de Bienestar en sus primeros años estuvo abocada a la creación y gestión de un sistema eficiente de contratación de trabajadores que asegurara una provisión permanente de mano de obra, resguardando derechos para ellos, lo que en la práctica funcionó como un verdadero contrato de trabajo, algunos años antes de la entrada en vigencia de la ley de contrato escrito. Por cierto, esta no fue la única labor del Departamento, pues su acción también ayudó al desarrollo de los propios departamentos de bienestar de cada oficina salitrera.

\section{Iniciativas de mejoramiento de la calidad de vida de la clase obrera}

Además de la provisión de la mano de obra, entre las actividades del Departamento de Bienestar de la APS estuvo la de contribuir a la organización de departamentos de bienestar en cada una de las oficinas de los asociados. Las actividades de estos departamentos locales se abocó a la educación, recreación, sanidad e higiene, pero sobre todo a mejoras en las viviendas, lo que representó entre el 50 y $60 \%$ de los gastos de bienestar en que incurrieron las compañías (Aguilera 2006:Cuadro 2). En general las viviendas pampinas que estaban destinadas a familias eran de 16 metros cuadrados, de dos o tres habitaciones, mayoritariamente construidas con placas de zinc acanaladas (calaminas), con poca capacidad de asilamiento para las condiciones del desierto (González Miranda 2002:212). El Estado estimuló la construcción de mejores viviendas y en 1925 eliminó los aranceles de importación a las placas de asbesto de techumbres que fueran destinadas a la construcción en las oficinas ${ }^{14}$; para septiembre del mismo año las compañías habían gastado casi $\$ 8,6$ millones en construcciones y $\$ 3,4$ en reparaciones, inversiones que permitieron contar con 19 mil viviendas de mejor calidad ${ }^{15}$. Si bien la construcción dio paso al concreto o al adobe, la calamina nunca fue reemplazada totalmente y continuó siendo el material de construcción dominante en la década de 1920, sobre todo en las viviendas de menor tamaño (ver Tabla 1).

La salud de los trabajadores también involucró la acción del Departamento de Bienestar de la APS y su primer gran desafío fue proveer de servicios médicos y hospitalarios modernos en los campamentos o en sus cercanías ${ }^{16}$. Las gestiones de la Asociación permitieron que a mediados de 1923 


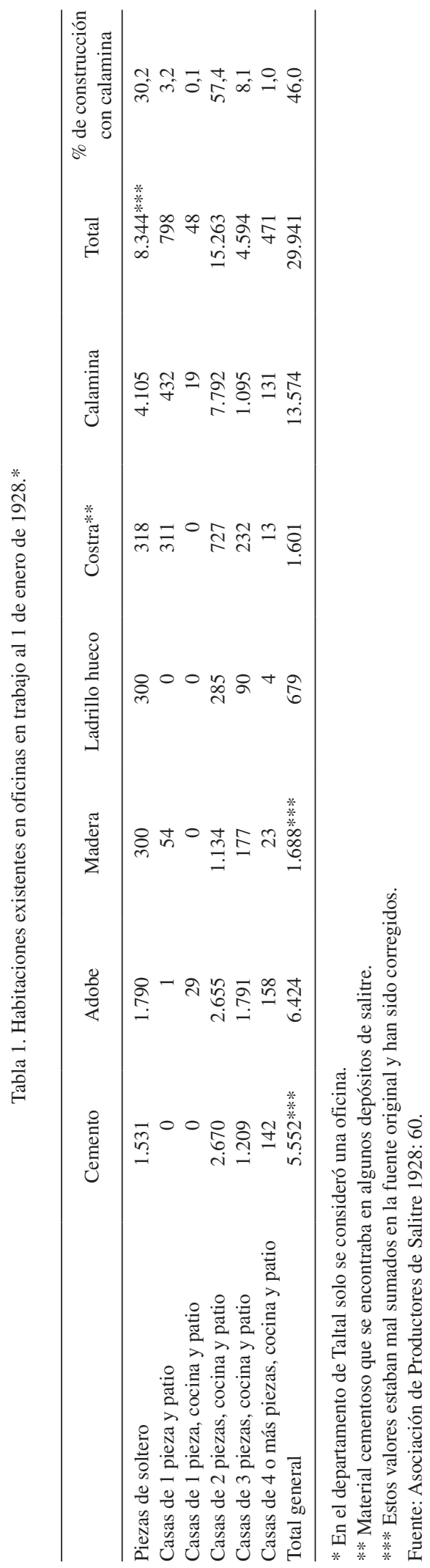

existieran 13 enfermerías y 12 maternidades, más el funcionamiento de 29 baños públicos en diversas oficinas. En 1923 se establecieron servicios de carros ambulancia en Tarapacá, Antofagasta y Tocopilla, inexistentes hasta ese momento ${ }^{17}$, lo que recibió apoyo del gobierno que en 1924 derogó los aranceles de importación en Tarapacá y Antofagasta para aumentar el número de estos vehículos ${ }^{18}$. Hacia 1925 se habían construido 18 hospitales, pero el personal era escaso: para atender a unas 60 mil personas había 38 médicos, 82 practicantes y 55 matronas ${ }^{19}$. El Departamento de Bienestar solo logró que las compañías se comprometieran a mantener un médico cada 2 mil obreros, y un practicante y matrona cada 150 , lo que en la mayoría de las oficinas se cumplía. No obstante estas mejoras, la oferta de medicamentos nunca alcanzó los requerimientos de la población (Asociación de Productores de Salitre 1928:36-37).

El combate al consumo de alcohol también se asoció a las medidas para mejorar las condiciones de vida de los trabajadores, así como para disminuir el ausentismo laboral. En 1923 la APS suprimió su venta en los campamentos, pero se mantuvo en los pueblos de la pampa, los que ofrecían múltiples opciones para su consumo ${ }^{20}$. Los pueblos del desierto eran lugares que estaban libres de la influencia de las compañías y cuyos habitantes se dedicaban a actividades de comercio y diversión (Damm 2013). A modo de ejemplo, el pueblo Pampa Unión tenía en 1924 menos de dos mil habitantes y existían 77 establecimientos que comercializaban alcohol, es decir, uno cada 3,9 personas $^{21}$. La presión de la Asociación hizo que en 1925 el gobierno restringiera la producción, circulación y consumo de alcohol en las zonas rurales de las provincias de Tarapacá y Antofagasta, salvo para uso médico o religioso ${ }^{22}$. Pero dicha medida se modificó en 1927 al reinstaurarse en los pueblos de la pampa la venta de bebidas fermentadas de menor graduación alcohólica, lo que fue criticado por las compañías (Asociación de Productores de Salitre 1928:99).

También fueron objeto de atención del Departamento de Bienestar los precios de los artículos de primera necesidad que eran comercializados en las pulperías de las oficinas. Por décadas la pulpería fue vista por los trabajadores como una forma de expoliación, quienes continuamente manifestaron su descontento con ellas. Esto, producto de que los precios de venta eran mayores en los campamentos a los de las ciudades costeras, que generalmente 
las pulperías eran propiedad de las compañías y que los obreros carecían de otras alternativas de consumo (González 2002:133-141). El directorio de la APS sugirió que se difundieran los precios y se permitiese el ingreso de vendedores ambulantes a los campamentos (lo que finalmente fue impuesto por la ley en 1924). Hacia mediados de 1925 la Asociación insistió que no existía ganancia en las pulperías, que lo obreros que recibían un salario fijo estaban satisfechos con los precios y que las quejas provenían de aquellos obreros que se regían bajo un sistema de trabajo a destajo ${ }^{23}$. La evidencia establecida por la Inspección del Trabajo de Antofagasta sugiere que en la segunda mitad de la década de 1920 los precios de las oficinas de dicha provincia estaban en muchos casos igual o bajo lo que se cobraba en Antofagasta -aunque no necesariamente al costo-, salvo tal vez por la carne (ver Tabla 2). Sin embargo, esto no supuso el fin de los conflictos por el consumo de artículos de primera necesidad. Según el inspector regional del trabajo de Tarapacá, la adulteración de pesos y medidas fue la solución para seguir obteniendo ganancias ${ }^{24}$, mientras que su par en Antofagasta informó que solo ocasionalmente las pulperías exhibían los precios ${ }^{25}$.

Un tema sensible en el Chile de la década de 1920 fue el de la educación, preocupación que se incorporó a las iniciativas de bienestar en la actividad salitrera. En aquellos años el Estado se comprometió con la formación escolar al dictar la Ley de Instrucción Primaria Obligatoria en 1920, acción que respondió a la baja cobertura escolar (Egaña 2000). En las provincias de Tarapacá y Antofagasta casi $40 \%$ de los niños eran analfabetos y cerca del $10 \%$ de la población en las salitreras estaba en edad escolar (Dirección General de Estadística 1925). Debido a las precariedades financieras del Estado, el gobierno de Alessandri determinó que las escuelas en las oficinas salitreras fuesen mixtas para aprovechar de mejor manera la infraestructura (Gonzáles Pizarro 2009). Si bien el Estado adquirió un compromiso para aumentar la cobertura escolar, en las zonas salitreras fueron las compañías las que asumieron el mayor costo de la educación pública, lo que se tradujo en la mantención y construcción

Tabla 2. Índice de precios de artículos de primera necesidad, 1926.

\begin{tabular}{|c|c|c|c|c|c|c|c|c|}
\hline \multirow[b]{2}{*}{ Artículos } & \multirow[b]{2}{*}{ Cantidad } & \multirow[b]{2}{*}{ Antofagasta } & \multicolumn{6}{|c|}{ Oficinas salitreras } \\
\hline & & & Chacabuco & Cecilia & $\begin{array}{l}\text { Higinio } \\
\text { Astoreca }\end{array}$ & Bonasort & Castilla & Dominador \\
\hline Aceite & Litro & 100 & 111 & 98 & 114 & 109 & 122 & 109 \\
\hline Arroz & Kilo & 100 & 88 & 89 & 86 & 114 & 114 & 100 \\
\hline Azúcar & Kilo & 100 & 81 & 94 & 94 & 94 & 94 & 94 \\
\hline Bototos & Cada par & 100 & 105 & 93 & 107 & 107 & 114 & 114 \\
\hline Café & Kilo & 100 & 75 & 80 & 100 & 140 & 140 & 100 \\
\hline Carbón & Kilo & 100 & 85 & 100 & 70 & 100 & 125 & 125 \\
\hline Carne & Kilo & 100 & 57 & 52 & 64 & 54 & 57 & 65 \\
\hline Fideos & Kilo & 100 & 78 & 101 & 76 & 101 & 101 & 95 \\
\hline Frejoles & Kilo & 100 & 88 & 112 & 88 & 96 & 117 & 112 \\
\hline Grasa & Kilo & 100 & 98 & 93 & 93 & 99 & 114 & 111 \\
\hline Harina & Kilo & 100 & 104 & 81 & 71 & 101 & 101 & 101 \\
\hline Jabón & Barra & 100 & 320 & 300 & 320 & 400 & 180 & 250 \\
\hline Leche & Tarro & 100 & 113 & 100 & 113 & 113 & 113 & 113 \\
\hline Lentejas & Kilo & 100 & 103 & 86 & 86 & 138 & 103 & 121 \\
\hline Maíz & Kilo & 100 & 143 & 111 & 93 & 167 & 111 & 148 \\
\hline Pan & Kilo & 100 & 63 & 63 & 63 & 81 & 75 & 75 \\
\hline Pantalones & Cada par & 100 & 100 & 93 & 100 & 80 & 100 & 100 \\
\hline Papas & Kilo & 100 & 146 & 146 & 98 & 146 & 146 & 146 \\
\hline Parafina & Litro & 100 & 125 & 125 & --- & 125 & 125 & 125 \\
\hline Sal cocina & Kilo & 100 & 67 & 67 & 83 & 100 & 67 & 67 \\
\hline Trigo & Kilo & 100 & 112 & 115 & 90 & 128 & 128 & 103 \\
\hline Velas & Paquete & 100 & 89 & 100 & 89 & 100 & 89 & 89 \\
\hline
\end{tabular}

Fuente: ANCh, FIA, vol. 66, Inspección Regional del Trabajo de Antofagasta, "Término medio precios artículos primera necesidad, $4^{\circ}$ trimestre, año 1926". 
de escuelas, compra de materiales didácticos e incluso el pago de los sueldos de profesores del sistema de enseñanza público (ver Tabla 3). En opinión del gerente de la Asociación, esto era un "firme propósito de cooperación" con el gobierno, pero cuyos esfuerzos resultaban infructuosos debido al nulo control y fiscalización sobre las escuelas públicas por parte de los inspectores estatales ${ }^{26}$.

Las iniciativas de bienestar de la APS estuvieron también encaminadas a disciplinar a los trabajadores y conseguir su autocontrol. Para ello se recurrió a la constitución de familias nucleares, ya que se creía que permitía fijar la residencia de los trabajadores, disminuir su movilidad espacial y su radicalismo político. En este periodo, el contexto general de la minería en Chile, existió una activa política empresarial para organizar las relaciones familiares obreras a partir del modelo de familia nuclear. Este fenómeno contó con respaldo estatal que se concretó en el establecimiento de oficinas de Registro Civil en algunos yacimientos, con el objetivo de facilitar la concreción de matrimonios (Aguilera 2016:246-250). Al igual que en otras partes del país, las uniones ilegítimas eran usuales en las parejas de clase obrera en la pampa; por ejemplo, en Antofagasta el $41 \%$ de los trabajadores salitreros que tenía familia no estaba casado ${ }^{27}$. La Dirección General del Trabajo elogió la decisión de la APS de contratar obreros con familias, manifestando esta última que se trataba de una política usual ${ }^{28}$. El matrimonio también era considerado como un elemento que disminuía la actividad criminal. De acuerdo con el intendente de Antofagasta, los delitos se debían al alcoholismo pero fundamentalmente a que los obreros no tenían constituido "legalmente sus hogares" 29 . Esta idea no era propia de dicha autoridad, sino que estuvo presente en el debate nacional respecto de la familia a fines del siglo XIX y principios del XX (Milanich 2009:226). No obstante, fijar la residencia de los trabajadores requirió de constantes esfuerzos por parte de las compañías, a causa de la arraigada costumbre de movilidad espacial de los hombres, que en opinión de la Asociación constituía un gasto enorme a la industria (Asociación de Productores de Salitre 1928:32). De acuerdo con un estudio de 1927, de los obreros que ocuparon puestos cuya duración era superior a seis meses, casi $83 \%$ abandonó la oficina antes de que sus labores concluyeran (Asociación de Productores de Salitre 1928:33).

En suma, la década de 1920 fue un periodo de crecientes inversiones de las compañías salitreras para mejorar las condiciones de vida de los obreros. Estas inversiones permitieron acceder a muchos obreros a beneficios propios de un régimen de bienestar y paternalismo industrial, lo que complementaba sus salarios, aunque estos beneficios nunca fueron suficientes para superar completamente las duras condiciones que debieron experimentar en su paso por la pampa.

\section{Intervención social y controversias entre la Asociación de Productores de Salitre y el Estado}

Desde fines del siglo XIX el Estado chileno desarrolló una creciente intervención social, entendida esta como la respuesta estatal a los problemas derivados de la cuestión social (Yáñez 2008:17), cuyo clímax se alcanzó en 1924-1925 al dictarse ciertas normas que regularon el contrato de trabajo y establecieron prestaciones de salud y previsión laboral para los trabajadores. Sin embargo, esta creciente actividad estatal puso en tensión algunas de las prácticas de bienestar industrial impulsadas por el sector minero. La Asociación públicamente no se opuso a la existencia de la legislación social, pero consideró que se aprobó con premura, se mostró contraria a la redacción de las leyes y cuestionó los costos de su aplicación. También culpó a estas

Tabla 3. Profesores fiscales en la provincia de Antofagasta, 1929.

\begin{tabular}{lcccc}
\hline \multicolumn{1}{c}{ Departamento } & Escuelas fiscales & Profesores fiscales & $\begin{array}{c}\text { Profesores pagados por } \\
\text { compañías salitreras }\end{array}$ & Alumno por cada profesor \\
\hline Antofagasta & 34 & 115 & 23 & 60 \\
Taltal & 15 & 40 & 1 & 50 \\
Tocopilla & 18 & 38 & 20 & 76 \\
El Loa & 7 & 13 & 24 & 62 \\
\hline
\end{tabular}

Fuente: ANCh, FIA, vol. 77, "Datos estadísticos correspondientes al mes de marzo de 1929”, Antofagasta, 11 de abril de 1929. 
leyes por el incremento de las huelgas y sostuvo que la mayoría de las solicitudes presentadas por los obreros al gobierno habían sido concedidas por los salitreros "de propia iniciativa hace ya mucho tiempo", beneficios que en algunos casos iban "más allá de lo que disponen las mismas leyes" ${ }^{30}$. Este argumento acerca de la necesidad de la legislación social, pero el cuestionamiento a su contenido y costos también fue compartido por otras entidades ligadas a la minería chilena, como la Sociedad Nacional de Minería (Aguilera 2016:239-241).

La legislación social puso en tensión algunas de las prácticas características de las relaciones laborales en la minería del salitre. La primera de ellas se originó por el sistema de pago del salario con fichas. Algunas semanas antes de que estas fuesen abolidas por las leyes de 1924, pero cuya aplicación entró en vigencia en marzo de 1925, la Junta Local Salitrera de Tarapacá comunicó al directorio de la Asociación la imposibilidad de suspender este sistema. Esta conclusión era compartida por el directorio de la APS, que sostenía que el dinero en efectivo siempre terminaba saliendo de circulación, por lo que se hacía necesario reponer las fichas ${ }^{31}$. En una reunión realizada en octubre de 1924 entre el gerente de la Asociación con el nuevo ministro de hacienda, el almirante Francisco Nef -quien integró la Junta de Gobierno militar que gobernó desde la caída del gobierno de Alessandri hasta fines de enero de 1925-, quedó en evidencia que las fichas habían sido abolidas al aprobarse la ley de contrato de trabajo en septiembre de 1924, la que estableció en su artículo 15 que los salarios de los obreros "deberán estipularse y ser pagados en moneda de curso legal, bajo pena de no ser válido el pago que se haga en otra forma" (Ley 4.053). Para tranquilizar a la Asociación, el ministro le señaló que se estaban acuñando monedas para enviar al norte y en otra oportunidad el delegado fiscal salitrero le hizo saber a uno de los directores de la APS que la suspensión de las fichas sería gradual. En este escenario, el directorio tuvo que reconocer "que ya no hay posibilidad de pedir una reconsideración de este acuerdo" 32 .

La legislación social también estableció el reconocimiento legal de los sindicatos, lo que abrió otro frente de controversias entre la APS y el Estado. Por ejemplo, en 1925 el intendente de Antofagasta apoyó la formación de sindicatos en actividades portuarias de embarque del salitre, pero la Asociación consideró que se trataba de sindicatos ilegales ${ }^{33}$ y en varias oportunidades el directorio de la Asociación discutió pedir al gobierno la derogación de las normas de sindicalización ${ }^{34}$. La postura de los sindicatos salitreros se orientó hacia su reconocimiento legal y contó con el respaldo de las autoridades locales, pero sus dirigentes fueron perseguidos por las compañías, ya que la ley no los protegía. Tanto la crisis salitrera de 1926 como la represión gubernamental contra anarquistas y comunistas de inicios de 1927 disminuyeron la acción sindical salitrera, la que se reactivó en 1928; y si bien estuvo considerablemente intervenida por el gobierno autoritario de Ibáñez, no impidió un enorme nivel de sindicalización. Hacia 1929 había más de 20 mil obreros en sindicatos salitreros, lo que representaba casi la mitad de dicha fuerza laboral. No obstante el alto nivel de sindicalización, sus efectos en mejorar las condiciones de los trabajadores fueron abruptamente abortados por las consecuencias de la Gran Depresión y el cierre de la mayoría de las oficinas a inicios de la década de 1930 (Rojas Flores 1993:130-132).

Otra fuente de controversias entre la Asociación y el Estado se debió a la autorización de ingreso de vendedores ambulantes a los campamentos. La ley de contrato laboral estableció la "libertad de comercio en el recinto de las poblaciones obreras dependientes de oficinas salitreras, de establecimientos mineros e industriales" (Ley 4.053). Con anterioridad la APS había recomendado a sus asociados permitir el acceso de vendedores ambulantes, pero solo algunas oficinas lo había autorizado y usualmente los vendedores eran rechazados bajo el argumento de que se trataba de agitadores políticos o que introducían alcohol en los campamentos. Si bien los comerciantes contaron posteriormente con respaldo legal, se desató una controversia entre las compañías y los comerciantes respecto de la interpretación de la ley; las primeras solo permitían su ingreso en un lugar determinado, mientras los segundos denunciaban que no se les permitía recorrer las calles y acusaron que eran hostilizados por los serenos e incluso los carabineros destinados en los campamentos ${ }^{35}$.

En gran parte las medidas adoptadas por la legislación social de 1924 fueron consideradas como beneficiosas por el Departamento de Bienestar de la Asociación, incluso algunas de ellas estuvieron en sus propuestas antes de que fueran consagradas en la ley. No obstante, al volverse obligaciones legales, perdieron el carácter benéfico que era otorgado por 
voluntad de las compañías, lo que socavó la relación propia del paternalismo industrial que subyacía en ello, mientras que otras desafiaron abiertamente el control de las compañías sobre los trabajadores, como el fin del sistema de salario en fichas, el reconocimiento legal de los sindicatos y la apertura de los campamentos a los vendedores ambulantes.

\section{Crisis salitrera y el mercado del trabajo}

Posiblemente el sistema de contratación instituido por el Departamento de Bienestar de la APS haya sido la forma de reclutamiento patronal de mayor alcance en la primera mitad del siglo XX, ello sin considerar la actividad estatal en la misma materia. Desde sus inicios y hasta mediados de 1925, el Departamento de Bienestar colocó 13.152 obreros en las oficinas, que junto con sus familias alcanzaron 18.250 personas $^{36}$. Paralelamente, a partir de 1923 el Estado chileno se había posicionado como en el principal colocador de trabajadores en industrias de diverso rubro, aunque también colaboró estrechamente con la Asociación de Productores de Salitre, especialmente durante el gobierno de Ibáñez. Durante 1928 la Asociación envió a las oficinas 32 mil obreros y casi 17 mil personas que los acompañaban (Monteon 1979:76-77). A pesar de la colaboración público-privada en el mercado de la mano de obra, a fines de 1924 el ministro de agricultura solicitó a la Asociación que suspendiera todos los enganches desde la ciudad de Chillán hacia el sur, lo que dejó fuera de su rango de acción a casi un tercio de la población del país ${ }^{37}$. A esto se sumó otro foco de atracción de trabajadores en la minería, al incrementarse la actividad extractiva de los grandes yacimientos cupríferos en Chuquicamata y Potrerillos, desde donde se enviaban enganchadores a las salitreras, lo que hizo que 10 mil obreros abandonaran las oficinas ${ }^{38}$. Los enganches de la Asociación también se vieron perjudicados por la apertura de la oficina salitrera Coya Norte -que luego pasó a llamarse María Elena- y que no estaba asociada $^{39}$.

La segunda mitad de la década de 1920 fue inestable para la actividad salitrera, lo que obligó al Departamento de Bienestar a regresar a muchos obreros y sus familias a sus lugares de origen, o suplir puestos de trabajo vacantes cuando una oficina reactivaba sus operaciones. La crisis del sector de 1925-1926 forzó el retorno al centro y sur del país a 18 mil personas ${ }^{40}$, lo que incrementó los gastos del
Departamento de Bienestar en varias oportunidades (ver Tabla 4). Paradójicamente en esta ocasión Chuquicamata y Coya Norte resultaron aliados para la Asociación, ya que ayudaron a absorber una parte de los desocupados ${ }^{41}$. El fin del uso extensivo de la mano de obra en la minería del salitre coincidió con los efectos de la Gran Depresión, la que se hizo sentir con fuerza en Chile entre 1931 y 1932, periodo en el que unos 50 mil trabajadores del salitre perdieron sus fuentes laborales, quienes junto con sus familias regresaron a sus lugares de origen o al centro del país, con la esperanza de encontrar mejores condiciones de vida. No obstante, la crisis fue generalizada y hacia 1932 cerca de 98 mil obreros y unos 25 mil empleados habían perdido sus fuentes laborales en todo Chile, lo que dificultó enormemente a los obreros del salitre su incorporación en otras actividades (Vergara 2014:62). La Gran Depresión también obligó el cierre de las oficinas que trabajaban con el sistema extractivo Shanks (Gonzales Pizarro 2005), el que se había originado a fines del siglo XIX, logrando sobrevivir solo aquellas oficinas que habían innovado en los métodos extractivos, cuyas compañías planificaron sus campamentos como verdaderas ciudades industriales (Garcés Feliú 1999:69).

Tabla 4. Presupuesto del Departamento de Bienestar de la APS, 1924-1929.

\begin{tabular}{cc}
\hline Año salitrero & Presupuesto \\
\hline $1924-1925$ & $£ 6.800,00$ \\
$1925-1926$ & $£ 9.100,00$ \\
$1926-1927$ & $£ 11.130,00$ \\
$1927-1928$ & $£ 9.600,00$ \\
$1928-1929$ & $£ 14.305,00$ \\
\hline
\end{tabular}

Fuente: ANCh, FAPS, vols. 59 y 82.

\section{Conclusión}

La década de 1920 representa un parteaguas en el que las ideas del liberalismo de fines del siglo XIX entraron en crisis, tanto por factores externos como internos en la historia de Chile. Un contexto estatal y patronal que aceptó mejorar sus relaciones con los trabajadores, así como la protesta y el radicalismo obrero que amenazaba con la revolución, favorecieron el establecimiento del Departamento de Bienestar Social de la APS. El Departamento mejoró algunos aspectos relacionados con las condiciones de vida de la clase obrera, sobre todo 
en relación con el acceso al trabajo y a asegurarles a los trabajadores algunos derechos, como el de retorno a sus lugares de origen, así como lograr una disminución parcial del costo de vida. Estas iniciativas no fueron únicamente otorgadas en virtud de un interés filantrópico (pero que tampoco debe descartarse), sino también para aumentar la productividad de los trabajadores y disminuir su radicalismo, lo que contó con el apoyo del Estado. No obstante, la Asociación experimentó dificultades en su aplicación; por un lado, la creciente intervención estatal en materias de derechos sociales contravino algunas de las prácticas de control social paternalistas de las compañías y, por el otro, hubo resistencia en las propias compañías a algunas de las acciones del programa de bienestar de la APS, sobre todo en sus primeros años. Bienintencionado o maquiavélico, el bienestar industrial en la minería del salitre fue tanto un discurso como una práctica de regeneración y modificación de las conductas de la clase trabajadora, aunque nunca logró una transformación completa de las condiciones de vida de los obreros y de sus familias. La crisis permanente que experimentó la actividad salitrera durante la década de 1920 desembocó en una creciente intervención estatal al finalizar dicho periodo, lo que forzó el desmantelamiento de la Asociación y de su Departamento de Bienestar. La Gran Depresión se hizo sentir con fuerza desde 1931 y prácticamente hizo desaparecer las compañías salitreras que utilizaban una fuerza laboral extensa, salvo por un puñado de ellas que habían innovado en métodos de obtención de salitre, las que establecieron campamentos modernos, como María Elena y Pedro de Valdivia, con programas de bienestar industrial que incorporaron las experiencias de bienestar de la década de 1920 que fueron lideradas por el Departamento de Bienestar de la Asociación de Productores de Salitre.

\section{Referencias Citadas}

Aguilera, J.

2016 Minería y Bienestar Social en Chile. 1916-1940. En El Orden Fabril. Paternalismo Industrial en la Minería Chilena 1900-1950, editado por E. Videla, H. Venegas y M. Godoy (pp. 219-252). América en Movimiento, Valparaíso.

Artaza, P.

2016 El reverso del bienestar. La creación del Departamento de Bienestar Social y el reforzamiento del control social en el norte grande a principios de los años 20. Estudios Atacameños 52: 49-68.

Asociación de Productores de Salitre.

1927 Exposición Leída por el Señor Presidente en la Junta General Ordinaria en 29 de Septiembre de 1927. Fisher y Cía. Impresores, Santiago.

Asociación de Productores de Salitre.

1928 Informe del Departamento de Bienestar Social a la 3 a Conferencia de Juntas Locales Salitreras. Sociedad Imprenta y Litografía Universo, Valparaíso.

Boletín de la Asociación de Productores de Salitre. 1921-1925.

Boletín de la Oficia del Trabajo, (12), 1919.

Bravo Elizondo, P. y Berry-Bravo, J.

2012 Era Chilena del Salitre. Tras la Ruta del Trabajo 18801979. Editorial Ricaaventura, Iquique.

Brito, A. y Ganter. R.

2014 Ciudad obrera: persistencias y variaciones en las significaciones del espacio. El caso de la siderúrgica Huachipato y su influencia en el desarrollo urbano del Gran Concepción. EURE 40(121): 29-53.

Couyoumdjian, R.

1986 Chile y Gran Bretaña Durante la Primera Guerra Mundial y la Postguerra, 1914-1921. Editorial Andrés Bello y Ediciones Universidad Católica de Chile, Santiago.

Damm, D.

2013 En los márgenes de lo oficial: desarrollo y asentamientos humanos en el Cantón Central. En La Sociedad del Salitre.
Protagonistas, Migraciones, Cultura Urbana y Espacios Públicos, editado por S. González Miranda (pp. 239-263). Ril Editores, Santiago.

De Shazo, P.

2007 Trabajadores Urbanos y Sindicatos en Chile: 19021927. DIBAM, Santiago.

Devés, E.

1997 Los que van a Morir te Saludan. Historia de una Masacre: Escuela Santa María, Iquique, 1907. LOM, Santiago.

Dirección General de Estadística.

1925 Censo de Población de la República de Chile, Levantado el 15 de Diciembre de 1920. Imprenta y Litografía Universo, Santiago.

Egaña, L.

2000 La Ley de Instrucción Primaria Obligatoria: un debate político. Revista Latinoamericana de Estudios Educativos XXVI(4): 9-39.

Farnsworth-Alvear, A.

2000 Dulcinea in The Factory. Myths, Morals, Men, and Women in Colombia's Industrial Experiment, 1905-1960. Duke University Press, Durham.

Garcés Feliú, E. 1999 Las Ciudades del Salitre. Orígenes. Santiago.

Godoy, M.

2015 Las casas de la empresa: paternalismo industrial y construcción de espacio urbano en Chile. Lota, 1900-1950. Universum 30(1): 115-136.

González Miranda, S.

2002 Hombres y Mujeres de la Pampa. Tarapacá en el Ciclo de Expansión del Salitre. Lom, Santiago.

González Miranda, S.

2006 Cruzando los mallkus. Las migraciones bolivianas pendulares durante las grandes crisis salitreras (1914-1933). Revista de Historia Social y de las Mentalidades 2(X): 155-191. 
González Miranda, S. (ed.)

2013 La Sociedad del Salitre. Protagonistas, Migraciones, Cultura Urbana y Espacios Públicos. Ril Editores, Santiago.

González Pizarro, J.

2005 Una visión de las oficinas salitreras del sistema Shanks. Notas sobre el periódico "El Abecé". Revista de Ciencias Sociales 15: 41-65.

González Pizarro, J.

2009 El imaginario pedagógico en las escuelas salitreras del desierto de Atacama. Revista de Historia Social y de las Mentalidades 13(2): 91-119.

Klubock, T. M.

1998 Contested Communities: Class, Gender, and Politics in Chile's El Teniente Cooper Mine, 1904-1951. Duke University Press, Durham.

Ley 4.053 (29 de septiembre de 1924). http://bcn.cl/1vw7x, (2 de diciembre de 2017)

Milanich, N.

2009 Children of Fate. Childhood, Class, and the State in Chile, 1850-1930. Duke University Press, Durham.

Monteon, $\mathrm{M}$.

1979 The enganche in the chilean nitrate sector, 1880-1930. Latin American Perspectives 6(3): 66-79.

Pavilack, J.

2011 Mining for the Nation: The Politics of Chile's Coal Communities from the Popular front to the Cold War. The Pennsylvania State University Press, University Park, Pennsylvania.

Pinto, J.

1998 Trabajos y Rebeldías en la Pampa Salitrera. Universidad de Santiago, Santiago.

Pinto, J. y Valdivia, V.

2001 ¿Revolución Proletaria o Querida Chusma? Socialismo y Alessandrismo en la pugna por la politización pampina (1911-1932). LOM, Santiago.

Recabarrean, F.

2010 La Matanza de San Gregorio, 1921: Crisis y Tragedia. LOM, Santiago.
Rojas Flores, J.

1993 La Dictadura de Ibánez y los Sindicatos (1927-1931).

Dirección de Bibliotecas, Archivos y Museos, Santiago.

Tomás Martínez, V.

2006 Salarios y programas de bienestar industrial en la empresa ferroviaria MZA (1915-1935)". Investigaciones de Historia Económica 4: 101-138.

Venegas, $\mathrm{H}$.

2014 Paternalismo industrial y control social. Las experiencias disciplinadoras en la minería del carbón en Chile, Lota y Coronel en la primera mitad del siglo XX. Les Cahiers ALHIM 28. Recuperado de http://alhim.revues.org/5099.

Venegas, H. y Morales, D.

2014 Trabajo tradicional en la minería carbonífera: una aproximación a los mayordomos (1920-1940). Diálogo Andino 45: 85-95.

Venegas, H., Videla, E. y Godoy, M. (Eds.).

2016 El Orden Fabril. Paternalismo Industrial en la Minería Chilena. 1900-1940. América en Movimiento, Valparaíso. Vergara, A.

2008 Copper Workers, International Bussines, and Domestic Politics in Cold War Chile. The Pennsylvania University Press, University Park, PA.

Vergara, A.

2014 Chilean workers and the Great Depression, 1930-1938. En Drinot, P. y Knight, A. (Eds.). The Great Depression in Latin America (pp. 51-80). Duke Universyty Press, Durham. Weinstein, B.

1996 For Social Peace in Brazil. Industrialists and the Remaking of the Working Class in São Paulo. 1920-1964. The University North Carolina Press, Chapel Hill.

Wray, $\mathrm{P}$

1996 Paternalism and its discontents: A case study. Work Employment \& Society 10(4): 701-715.

Yáñez, J. C.

2008 La Intervención Social en Chile, 1907-1932. Ril Editores, Santiago.
1 Esta entidad fue un cartel industrial que agrupó a las principales compañías salitreras y surgió en 1919 como respuesta a una posible intervención estatal en la comercialización del salitre (Couyoumdjian, 1986:188).

2 Boletín de la Asociación de Productores de Salitre, Valparaíso, marzo de 1921, p. XXXIX.

3 Boletín de la Oficia del Trabajo, $\mathrm{n}^{\circ}$ 12, 1919, pp. 171-203.

4 Archivo Nacional de Chile, Fondo Asociación de Productores de Salitre (en adelante ANCh, FAPS), Actas, vol. 20, 24 de junio de 1921, p. 76, 14 de julio de 1921, p. 92, 01 de diciembre de 1921, p. 207 y 29 de octubre de 1921, p. 178.

5 ANCh, FAPS, Actas, vol. 20, 18 de mayo de 1922, p. 334 y vol. 33, 9 de noviembre de 1922, p. 95. El borrador del reglamento de enganche estuvo listo a mediados de 1922 , ver vol. 33, 8 de septiembre de 1922, p. 48.

6 ANCh, FAPS, Actas, vol. 33, 7 de diciembre de 1922, p. 119.

7 ANCh, FAPS, Actas, vol. 33, 3 de agosto de 1922, p. 13.
8 ANCh, FAPS, Actas, vol. 33, 1 de junio de 1923, p. 268; 26 de julio de 1923, p. 306 y 2 de agosto de 1923, p. 33.

9 ANCh, FAPS, vol. 33, 14 de junio de 1923, p. 281 y 09 de agosto de 1923, p. 316. Boletín de la Asociación de Productores de Salitre, Valparaíso, septiembre de 1923, p. 998.

10 ANCh, FAPS, Actas, vol. 33, 22 de noviembre de 1923, p. 382. El directorio acordó abrir una oficina de contratación en la sureña ciudad de Temuco, ver vol. 33, 11 de octubre de 1923 , p. 357.

11 ANCh, FAPS, Actas, vol. 46, 17 de enero de 1924, p. 16 Uno de los directores sugirió que se esperara hasta abril para reanudar los enganches, una vez pasadas las cosechas, señalando además que se debía considerar que el jornal de los trabajadores agrícolas se había doblado hasta alcanzar $\$ 4$.

12 ANCh, FAPS, Actas, vol. 33, 29 de noviembre de 1923, p. 385 y vol. 82,31 de enero de 1929 , p. 390. La presencia 
de trabajadores bolivianos en las salitreras fue la mayor entre los trabajadores extranjeros. Hacia 1922 representaba cerca de $14 \%$ de la mano de obra (González Miranda, 2006).

13 Boletín de la Asociación de Productores de Salitre, Valparaíso, septiembre de 1921, pp. IV-VII.

14 Boletín de la Asociación de Productores de Salitre, Valparaíso, febrero de 1925, p. 131.

15 Boletín de la Asociación de Productores de Salitre, Valparaíso, septiembre de 1925, p. 895.

16 Boletín de la Asociación de Productores de Salitre, Valparaíso, junio de 1921, p. XI.

17 Boletín de la Asociación de Productores de Salitre, Valparaíso, septiembre de 1923, p. 1022.

18 Boletín de la Asociación de Productores de Salitre, Valparaíso, diciembre de 1924, p. 1409.

19 Boletín de la Asociación de Productores de Salitre, Valparaíso, julio de 1925, p. 715.

20 Boletín de la Asociación de Productores de Salitre, Valparaíso, septiembre de 1923, p. 998.

21 Archivo Nacional de Chile, Fondo Intendencia de Antofagasta (en adelante ANCh, FIA), vol. vol. 46, "Comunicación del subdelegado de Unión y Sierra Gorda al intendente de Antofagasta", Unión, 13 de noviembre de 1924.

22 Boletín de la Asociación de Productores de Salitre, Valparaíso, octubre de 1925, pp. 868-869.

23 Boletín de la Asociación de Productores de Salitre, Valparaíso, julio de 1925, pp. 716-717.

24 Archivo Nacional de Chile, Fondo Dirección del Trabajo (en adelante ANCh, FDT), vol. 124, "Comunicación del inspector regional del trabajo de Tarapacá a la Dirección General del Trabajo", Iquique, 16 de septiembre de 1926.

25 ANCh, FDT, vol. 145, "Comunicación del inspector regional del trabajo de Antofagasta al director general del trabajo", Antofagasta, 6 de septiembre de 1927.

26 Boletín de la Asociación de Productores de Salitre, Valparaíso, enero de 1925, p. 6. Hacia 1927 existía solo un visitador de escuelas en la provincia de Tarapacá y uno en la de Antofagasta (Asociación de Productores de Salitre, 1927:26)

27 ANCh, FAPS, Actas, vol. 33, 12 de julio de 1923, p. 299.
28

ANCh, FDT, vol. 142, "Carta de la Asociación de Productores de Salitre a la Dirección General del Trabajo, Valparaíso, 29 de junio de 1927.

29 ANCh, FIA vol. 57, "Comunicación del intendente de Antofagasta al ministro del interior", Antofagasta, 2 de septiembre de 1927, p. 11.

30 Boletín de la Asociación de Productores de Salitre, Valparaíso, septiembre de 1925, pp. 885-886. Entre 1924 y 1925 hubo un aumento en la movilización obrera que se encontró ligada a condiciones externas a los derechos que entregó la legislación social (DeShazo, 2007:300 y 304)

31 ANCh, FAPS, Actas, vol. 46, 28 de agosto de 1924, p. 252.

32 ANCh, FAPS, Actas, vol. 46, 9 de octubre de 1924, p. 272, 23 de octubre de 1924, p. 281. Boletín de la Asociación de Productores de Salitre, Valparaíso, noviembre de 1924, pp. 1264-1265.

33 ANCh, FAPS, Actas, vol. 59, 24 de septiembre de 1925, p. 88.

34 ANCh, FAPS, Actas, vol. 46, 2 de enero de 1925, p. 321, vol. 82, 9 de junio de 1927, 17 de enero de 1929, p. 88.

35 ANCh, FIA, vol. 45, "Carta del secretario general de la Sociedad Internacional de Comerciantes de Pampa Unión al intendente de Antofagasta", Pampa Unión, 31 de agosto de 1926; vol. 50, "Comunicación del inspector del Bienestar Social de la Asociación de Productores de Salitre al intendente de Antofagasta", Antofagasta, 15 de junio de 1927; vol. 61, "Comunicación del presidente de la Sociedad de Comerciantes de Tocopilla al gobernador de Tocopilla", Tocopilla, 19 de noviembre de 1928.

36 Revista de la Habitación, año I, n ${ }^{\circ}$, octubre de 1925, p. 32.

37 ANCh, FAPS, Actas, vol. 46, 4 de diciembre de 1924, p. 296.

38 ANCh, FAPS, Actas, vol. 46, 5 de febrero de 1925, p. 334.

39 ANCh, FAPS, Actas, vol. 46, 8 de octubre de 1925, p. 110.

40 Revista de la Habitación, Santiago, año I, $\mathrm{n}^{\circ}$ 1, septiembreoctubre de 1926, pp. 47-48; ANCh, FAPS, Actas, vol. 59, "Sesión ordinaria del directorio", 6 de mayo de 1926, p. 221.

41 ANCh, FAPS, Actas, vol. 59, 15 de julio de 1926, p. 269. 
